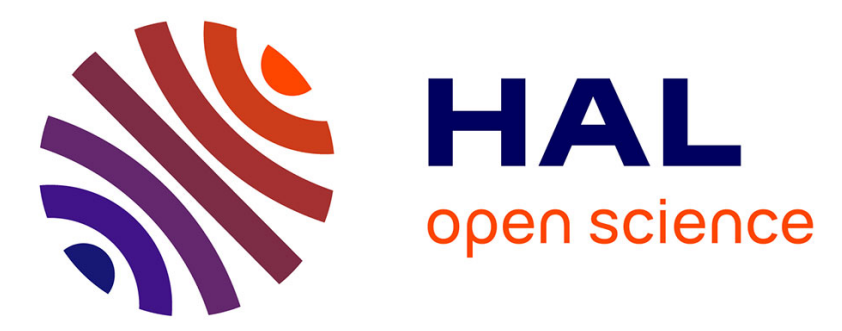

\title{
Comparison of Face-Down and Seated Position After Idiopathic Macular Hole Surgery: A Randomized Clinical Trial
}

Alexandre Guillaubey, Laure Malvitte, Pierre Olivier Lafontaine, Nicolas Jay, Isabelle Hubert, Alain Bron, Jean Paul Berrod, Catherine Creuzot-Garcher

\section{To cite this version:}

Alexandre Guillaubey, Laure Malvitte, Pierre Olivier Lafontaine, Nicolas Jay, Isabelle Hubert, et al.. Comparison of Face-Down and Seated Position After Idiopathic Macular Hole Surgery: A Randomized Clinical Trial. American Journal of Ophthalmology, 2008, 146 (1), pp.128-134.e1. 10.1016/j.ajo.2008.02.029 . hal-02138928

\section{HAL Id: hal-02138928 \\ https://hal.inria.fr/hal-02138928}

Submitted on 30 May 2020

HAL is a multi-disciplinary open access archive for the deposit and dissemination of scientific research documents, whether they are published or not. The documents may come from teaching and research institutions in France or abroad, or from public or private research centers.
L'archive ouverte pluridisciplinaire HAL, est destinée au dépôt et à la diffusion de documents scientifiques de niveau recherche, publiés ou non, émanant des établissements d'enseignement et de recherche français ou étrangers, des laboratoires publics ou privés. 


\title{
Comparison of Face-Down and Seated Position After Idiopathic Macular Hole Surgery: A Randomized Clinical Trial
}

\author{
ALEXANDRE GUILLAUBEY, LAURE MALVITTE, PIERRE OLIVIER LAFONTAINE, NICOLAS JAY, \\ ISABELLE HUBERT, ALAIN BRON, JEAN PAUL BERROD, AND CATHERINE CREUZOT-GARCHER
}

- PURPOSE: To compare two therapeutic modalities on anatomic and functional results after idiopathic macular hole $(\mathrm{MH})$ surgery: seated vs face-down position.

- DESIGN: Multicenter, prospective, randomized trial.

- METHODS: SETTING: University Hospital Dijon and University Hospital Nancy. PATIEnTs: One hundred and forty-four patients (150 eyes) were enrolled and randomly separated into two groups for postoperative position: for the 72 eyes in the $\mathrm{PO}$ group and the 78 eyes in the P1 group, the patients were asked to keep the seated (PO group) and the face-down position (P1 group) after the idiopathic MH surgery. INTERVENTION: All patients underwent a complete vitrectomy with a fluid-air exchange and an intraocular gas tamponade. After the surgery, patients were asked to keep one of the two randomly chosen positions for five days. MAIN OUTCOME MEASURES: Best-corrected visual acuity (VA), fundus examination, and macular optical coherence tomography were performed before and six months after surgery.

- RESULTS: The overall anatomic success rate was $92.7 \%$. The idiopathic MH sealed in 63 of 72 PO eyes $(87.5 \%)$ and 76 of $78 \mathrm{P} 1$ eyes $(97.4 \%)(P=.027)$. The mean VA increased from 0.86 to $0.61 \operatorname{logMAR}$ ( 0.88 to 0.61 in $\mathrm{PO}$ and 0.84 to 0.60 in P1). However, in a post hoc analysis based on the size of the idiopathic $\mathrm{MH}$, the success rate in idiopathic MHs smaller than $400 \mu \mathrm{m}$ was not influenced by the postoperative position $(P=.47)$.

- CONCLUSIONS: A face-down postoperative position is highly recommended in holes larger than $400 \mu \mathrm{m}$. The size of the idiopathic $\mathrm{MH}$ seems to be an important factor affecting outcome. (Am J Ophthalmol 2008;146:128-134. (C) 2008 by Elsevier Inc. All rights reserved.)

\footnotetext{
AJO.com Supplemental Material available at AJO.com.

Accepted for publication Feb 28, 2008.

From the Department of Ophthalmology, University Hospital Dijon, Dijon, France (A.G., L.M., P.O.L., A.B., C.C.-G.); and the Departments of Statistics (N.J.) and Ophthalmology, University Hospital Nancy, Nancy, France (I.H., J.P.B.).

Inquiries to Catherine Creuzot-Garcher, Service d'ophtalmologie, CHU Dijon, Rue du Faubourg Raines, 21000 Dijon, France; e-mail: catherine.creuzot-garcher@chu-dijon.fr
}

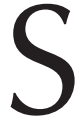
INCE 1991, STAGE 2, 3, AND 4 IDIOPATHIC MACULAR holes $(\mathrm{MHs})^{1}$ have benefited from an effective treatment as described by Kelly and Wendel: ${ }^{2}$ pars plana vitrectomy, removal of adherent cortical vitreous, stripping of epiretinal membranes, total gas-fluid exchange, and intraocular tamponade with a nonexpansive gas (sulfur hexafluoride gas [SF6]), with occiput-up postoperative positioning for one week. Closure is now obtained in a large proportion of cases. ${ }^{3}$

Modifications have been proposed to increase the rate of closure: different gases were used (SF6; hexafluoroethane [C2F6]; octafluoropropane $[\mathrm{C} 3 \mathrm{~F} 8])^{4}$ for intraocular tamponade, internal limiting membrane (ILM) peeling was proposed with or without dye, ${ }^{5-7}$ and the efficacy of adjuvant treatments such as transforming growth factor (TGF) $-\beta,{ }^{8-10}$ autologous platelets, ${ }^{11-13}$ and autologous serum were analyzed. ${ }^{14}$ The complication rate is relatively low and recent attempts have been made to simplify the surgical technique using transconjunctival sutureless surgery. ${ }^{15-17}$

However, postoperative face-down positioning after idiopathic $\mathrm{MH}$ surgery remains a limiting factor because of obesity, old age, arthritis, and other causes of mobility loss. The duration of positioning and the restrictions inherent to the position remain real problems for patients living alone. The face-down position can also increase the immobilization period, leading to thrombosis, embolism, and neurologic complications. ${ }^{18,19}$ Some authors have suggested using silicone oil to avoid these positioning problems. ${ }^{20-22}$ However, since the success rate with silicone oil was not as good as it was with gas, silicone oil has been largely abandoned.

The very good prognosis for small $\mathrm{MHs}$ and the morbidity of occiput-up positioning for one week led some authors to stop postoperative positioning, showing encouraging results. ${ }^{23,24}$ To the best of our knowledge, there has been no comparative, randomized trial evaluating the influence of face-down positioning after $\mathrm{MH}$ surgery on the anatomic and functional results vs no positioning at all. We undertook this study to compare the usual face-down position with a seated position. The comfortable seated position was chosen to prevent the patient from looking up after $\mathrm{MH}$ surgery. 


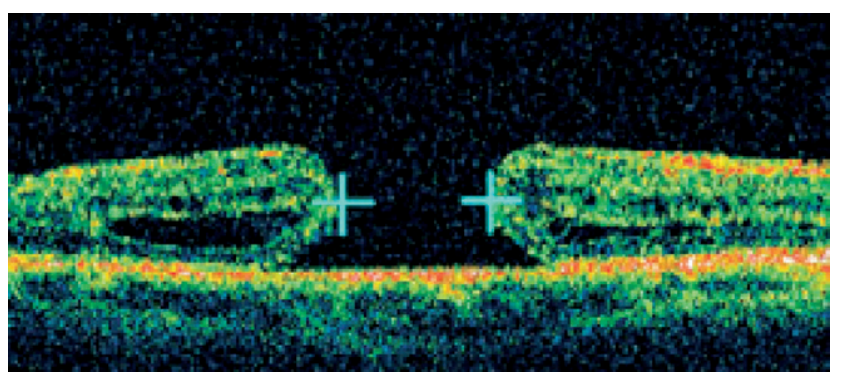

FIGURE 1. Optical coherence tomography (OCT) of a macular hole $(\mathrm{MH})$ and the measure of its size using calipers. Six radial scans were performed and the largest diameter was recorded for analysis.

\section{METHODS}

A PROSPECTIVE, INTERVENTIONAL, COMPARATIVE AND randomized clinical trial was conducted in 150 eyes of 144 consecutive patients undergoing $\mathrm{MH}$ surgery in two academic centers between July 1, 2004 and January 31, 2006. Patients had complete information about the study and the risks of the surgical procedure, especially retinal detachment (RD), and gave their written consent before surgery.

Patients with stage 2, 3, and 4 idiopathic MHs according to Gass ${ }^{1}$ and confirmed by optical coherence tomography (OCT) were included. Exclusion criteria were an axial length longer than $27 \mathrm{~mm}$, a previous

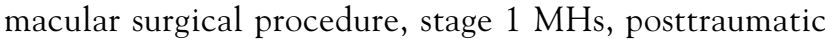
or other secondary $\mathrm{MHs}$, and inability to assume a correct face-down position.

Symptom duration was recorded and visual acuity (VA) was measured with projected-light Snellen charts converted to logarithm of minimal angle of resolution $(\log M A R)$. A complete ocular examination was performed in each patient, including anterior segment evaluation, intraocular pressure (IOP) measurement, fundus, careful peripheral retina examination, axial length measurement, and macular OCT (Stratus OCT III; Carl Zeiss Meditec, Dublin, California, USA), before and three and six months after the surgical procedure. The largest diameter of the idiopathic $\mathrm{MH}$ was measured with OCT (Figure 1).

All patients underwent the same surgical procedure: an extensive three-port pars plana vitrectomy using 20-gauge instrumentation. A peristaltic or venturi pump was used with maximum vacuum set between 200 and $500 \mathrm{~mm} \mathrm{Hg}$ according to the surgeon's preference, to obtain posterior vitreous detachment. The posterior hyaloid was generally attached to the disk (stage 2 and 3 ) and the macula (stage 2) and was lifted either with the vitreous cutter probe or with an active suction through a blunt cannula. Then the ILM was systematically removed using microforceps without indocyanine green or any other dye. Vitrectomy was completed, especially at the vitreous base. The retinal
TABLE 1. Patient Characteristics Before Idiopathic Macular Hole Surgery: The Idiopathic Macular Hole Stage is Clinical and does not use the Optical Coherence Tomography size.

\begin{tabular}{|c|c|c|c|}
\hline & \multirow[b]{2}{*}{ Total } & \multicolumn{2}{|c|}{ Positioning } \\
\hline & & Seated & Face-down \\
\hline Eyes, n (\%) & $150(100 \%)$ & 72 (48\%) & 78 (52\%) \\
\hline Male, n (\%) & $52(35 \%)$ & 25 (48\%) & $27(52 \%)$ \\
\hline Female, n (\%) & $98(65 \%)$ & 47 (48\%) & $51(52 \%)$ \\
\hline Age, mean ( $\pm S D)$ & $69( \pm 9.5)$ & $68( \pm 9.6)$ & $69( \pm 9.4)$ \\
\hline \multicolumn{4}{|l|}{ OCT MH size } \\
\hline$<400 \mu \mathrm{m}, \mathrm{n}(\%)$ & $70(47 \%)$ & $33(47 \%)$ & 37 (53\%) \\
\hline$>400 \mu \mathrm{m}, \mathrm{n}(\%)$ & $80(53 \%)$ & $39(49 \%)$ & $41(51 \%)$ \\
\hline \multicolumn{4}{|l|}{ MH clinical stage } \\
\hline $2, \mathrm{n}(\%)$ & $14(9 \%)$ & $5(36 \%)$ & $9(64 \%)$ \\
\hline $3, \mathrm{n}(\%)$ & $112(75 \%)$ & $56(50 \%)$ & $56(56 \%)$ \\
\hline 4, n (\%) & $24(16 \%)$ & $11(46 \%)$ & $13(54 \%)$ \\
\hline
\end{tabular}

$\mathrm{MH}=$ macular hole; $\mathrm{OCT}=$ optical coherence tomography

TABLE 2. Intraocular Gas Used During the Surgery was Dependent of Idiopathic Macular Hole Size: Anatomic Results According to Postoperative Position

\begin{tabular}{|c|c|c|c|c|c|c|}
\hline Hole Size & $\begin{array}{c}\text { P1 } \\
\text { Success }\end{array}$ & $\begin{array}{l}\text { P1 } \\
\text { Failure }\end{array}$ & $\begin{array}{c}\text { PO } \\
\text { Success }\end{array}$ & $\begin{array}{l}\text { Po } \\
\text { Failure }\end{array}$ & Total & Gas \\
\hline $0-500 \mu \mathrm{m}$ & 57 & 1 & 42 & 3 & \multicolumn{2}{|c|}{103 SF6 20\% } \\
\hline $500-800 \mu \mathrm{m}$ & 17 & 1 & 19 & 5 & \multicolumn{2}{|c|}{42 C2F6 17\% } \\
\hline $800-1000 \mu \mathrm{m}$ & 2 & 0 & 2 & 1 & \multicolumn{2}{|c|}{5 C3F8 14\% } \\
\hline
\end{tabular}

P0 = seated position; P1 = face-down position.

periphery was carefully examined. Finally, total fluid-air exchange (FAE) was performed and a nonexpanding mixture of air and SF6 (20\%) was used for pneumatic tamponade in idiopathic MHs less than $500 \mu \mathrm{m}$, air and C2F6 (17\%) in idiopathic MHs larger than $500 \mu \mathrm{m}$, and air and C3F8 (14\%) in idiopathic MHs larger than 800 $\mu \mathrm{m}$. Combined phacoemulsification could be done with posterior chamber intraocular implantation when needed. All surgeries were performed under peribulbar anesthesia. Patients were randomized following completion of the surgery into two groups: P0 and P1. After surgery, the P0 group patients were asked to keep a seated position and $\mathrm{P} 1$ patients a strict face-down position eight hours a day intermittently while awake for five days (see Supplemental Figure at AJO.com). Intensive recommendations were given to the patients prior to their return home to ensure that the correct position was adopted. If the patients could not maintain the position at home, then they were accommodated in a convalescent home. In all cases, patients were asked not to look up. If the $\mathrm{MH}$ was still open at the one-month postoperative visit, the patient had 


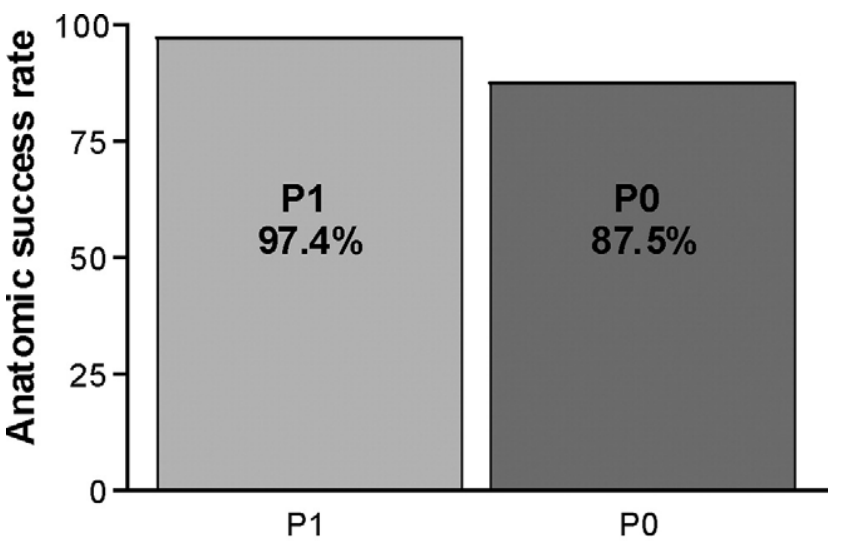

Postoperative position

FIGURE 2. Idiopathic MH surgery success rates according to the position. Face-down position got better anatomic results. P1: face-down position; P0: seated position. Fisher exact test; $P=.027$.

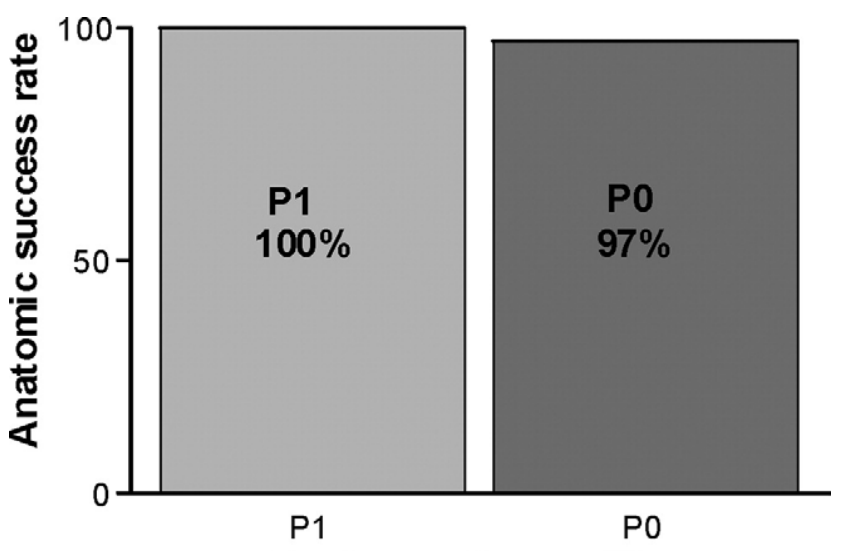

Postoperative position

FIGURE 3. Idiopathic MH surgery success rates for holes smaller than $400 \mu \mathrm{m}$ according to the postoperative position. There was no significant difference between the two positions. P1: face-down position; P0: seated position. Fisher exact test; $P=.47$.

another surgical procedure followed by adoption of the classical face-down postoperative position.

The primary endpoint was anatomic closure of the hole after one surgical procedure confirmed by OCT. The secondary endpoint was best-corrected VA change between the preoperative and the six-month visit. The VA results were analyzed according to the surgical procedure: with or without combined phacoemulsification. A secondary analysis was performed considering the size of the idiopathic $\mathrm{MH}$ determined by OCT: MHs were separated into two subgroups, small MHs $(<400 \mu \mathrm{m})$ and large ones $(>400 \mu \mathrm{m})$. Data were analyzed using the Fisher exact test, the paired $t$ test, and the Mann-Whitney $U$ test. The threshold of statistical significance was set at $P<.05$.

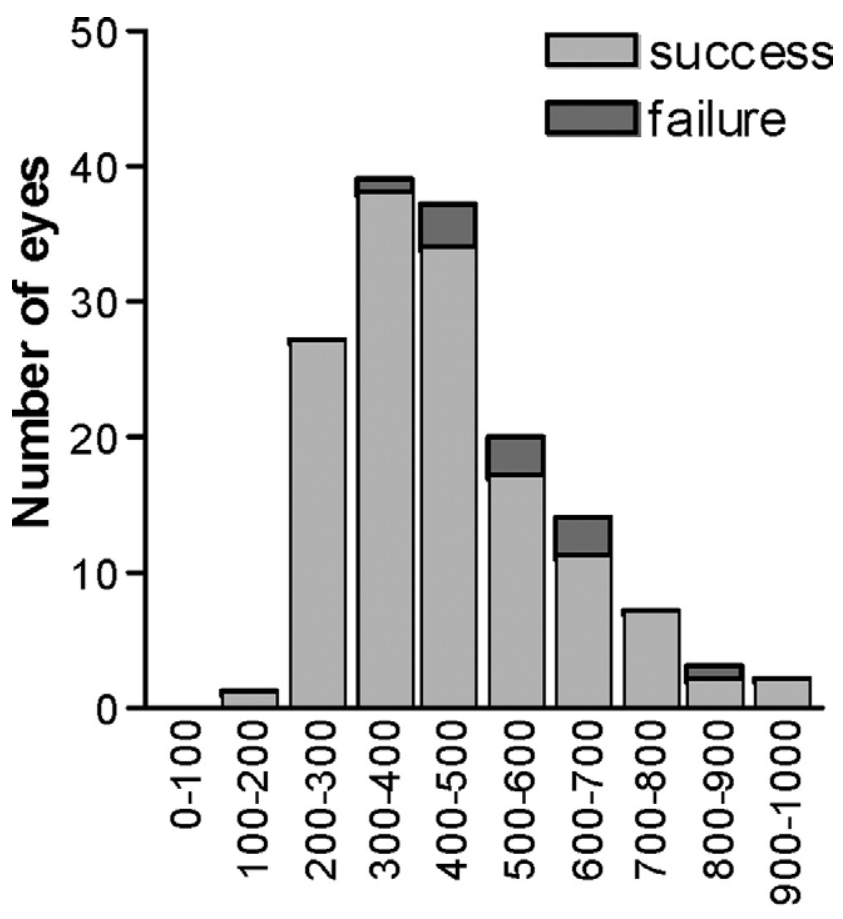

\section{Idioipathic Macular Hole initial size $(\mu \mathrm{m})$}

FIGURE 4. Anatomic results of all the idiopathic MH surgeries according to initial size of the holes.

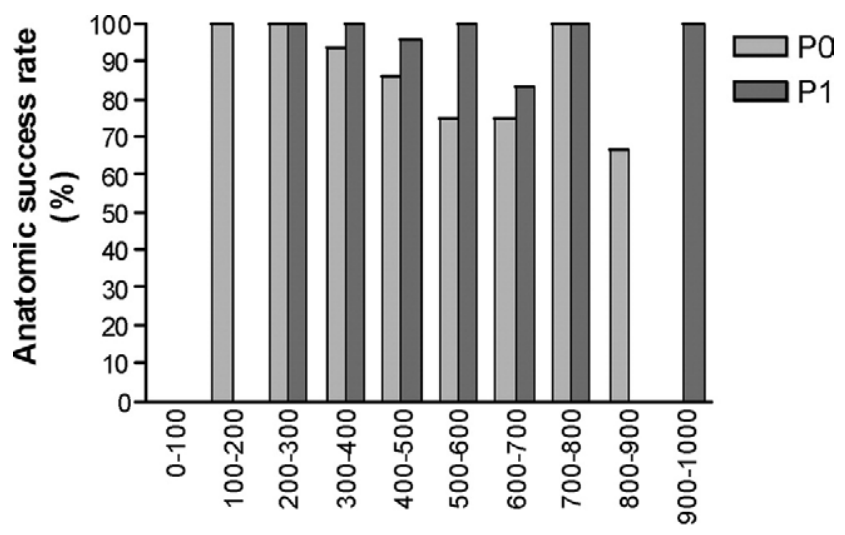

Idiopathic Macular Hole initial size $(\mu \mathrm{m})$

FIGURE 5. Idiopathic MH surgery success rate according to initial size of the hole and postoperative position. Seated postoperative position success rates decrease for holes larger than $400 \mu \mathrm{m}$. P0: seated position; P1: face-down position.

\section{RESULTS}

ONE HUNDRED AND FIFTY EYES WERE INCLUDED IN THIS prospective series; patient characteristics are given in Table 1. The intraocular gases used are given in Table 2. The minimum follow-up was six months (mean, 15 


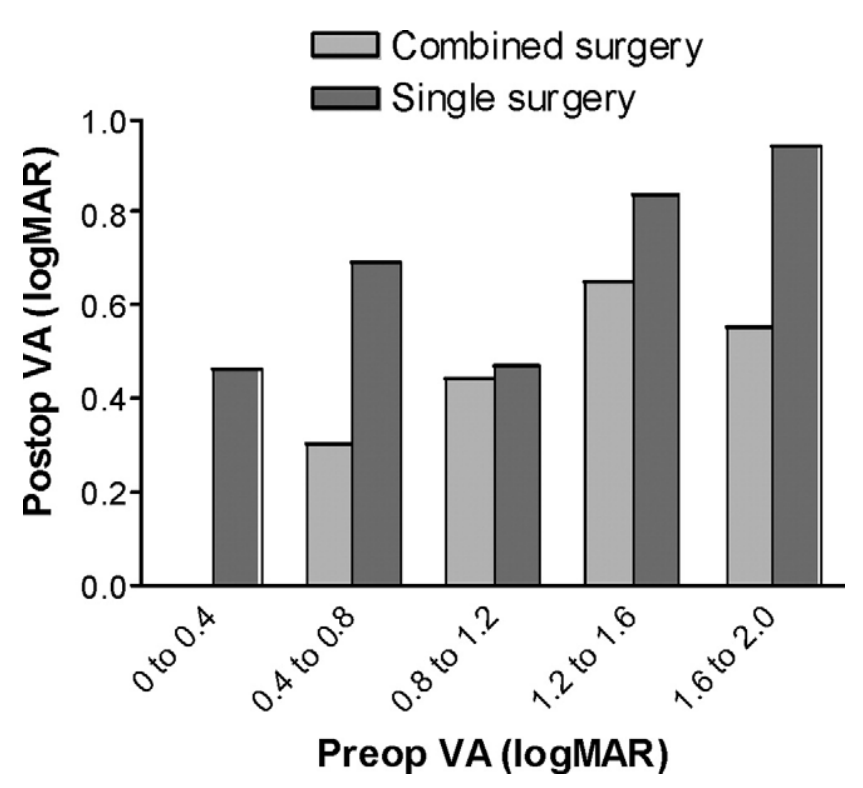

FIGURE 6. Visual acuity (VA) changes after idiopathic $\mathrm{MH}$ surgery according to the type of surgical procedure: single $\mathrm{MH}$ surgery or MH surgery combined with cataract extraction and intraocular lens. Preop VA: preoperative visual acuity; Postop VA: postoperative visual acuity.

months; range, six to 25). Overall, $92.7 \%$ of the $\mathrm{MHs}$ were closed with one operation (139 anatomic successes out of 150 idiopathic $\mathrm{MH}$ surgeries). For the $\mathrm{PO}$ group, the anatomic success rate was $87.5 \%(63 / 72)$ vs $97.4 \%(76 / 78)$ for the P1 group. The difference between P0 and P1 was significant $(P=.027)$ (Figure 2). Mean VA increased from 0.86 to $0.61 \log \mathrm{MAR}(P=.001)$. The mean VA improved from 0.88 to $0.61(P=.006)$ and from 0.84 to $0.60(P=$ $.027)$ in the $\mathrm{PO}$ and $\mathrm{P} 1$ groups, respectively. There was no significant difference between the mean VA of the PO and $\mathrm{P} 1$ groups $(P=.923$ for preoperative data and $P=.943$ for postoperative data). The final VA improved by more than two lines in $54(61.4 \%)$ of the 88 eyes without cataract extraction, with no statistically significant difference between the two positions $(P>.999)$.

The results obtained for idiopathic $\mathrm{MH}$ closure according to the size of the idiopathic $\mathrm{MH}$ were retrospectively analyzed. We found that in small MHs (less than $400 \mu \mathrm{m}$ in diameter), the overall anatomic success rate was $98.6 \%$ (69/70): $97.0 \%$ (32/33) and $100.0 \%$ (37/37) for P0 and P1, respectively (Figure 3$)$. The difference between $\mathrm{PO}$ and $\mathrm{P} 1$ in small idiopathic $\mathrm{MHs}$ was not significant $(P=.47)$. On the contrary, in large $\mathrm{MHs}$ (more than $400 \mu \mathrm{m}$ in diameter), the overall anatomic success rate was 70/80 (87.5\%); 31/39 (79.5\%); and 39/41 (95.1\%) for P0 and P1, respectively. The difference between $\mathrm{PO}$ and $\mathrm{P} 1$ in large idiopathic $\mathrm{MHs}$ was significant $(P=.045)$. Whatever the position, the difference between small $(<400 \mu \mathrm{m})$ and large idiopathic $\mathrm{MHs}(>400 \mu \mathrm{m})$ was significant $(P=$ .011) (Figures 4 and 5).
The 62 combined surgeries for idiopathic $\mathrm{MH}$ and phacoemulsification were also analyzed. There were 30 and 32 eyes in the $\mathrm{PO}$ and $\mathrm{P} 1$ groups, respectively. There were 28 idiopathic MHs smaller than $400 \mu \mathrm{m}$ and 34 idiopathic $\mathrm{MHs}$ larger than $400 \mu \mathrm{m}$. The three anatomic failures were in the subgroup of patients with idiopathic $\mathrm{MHs}$ larger than $400 \mu \mathrm{m}$ who adopted the seated position. The anatomic success rate was $96.8 \%$ for combined surgery vs $89.8 \%$ for a single procedure $(P=.124)$. The functional results showed VA means increasing from 1.1 to 0.47 and the final VA improved by two lines or more in 55 (89\%) of the 62 eyes with combined surgery (Figure 6).

We observed 11 anatomic failures in this study: three patients refused another treatment and eight underwent a second procedure with total FAE and intraocular gas tamponade, leading to anatomic success in five of them.

Severe complications were $12 \mathrm{RDs}$, four and eight in the $\mathrm{P0}$ and $\mathrm{P} 1$ groups $(P=.373)$, respectively. Four RDs were inferior, four RDs were superior, and four RDs were total, two with vitreoretinal proliferation. RDs occurred from one to 85 days after surgery $(45 \pm 30)$. Eight were treated successfully with one operation. Four needed from one to two additional surgeries. There was no endophthalmitis and no chronic elevation of IOP.

\section{DISCUSSION}

PROPER IDIOPATHIC MH MANAGEMENT REQUIRES THAT the edges of the hole be kept dry with the gas tamponade and the closure of the hole be achieved within a few days.

Intraocular gas tamponade has two main properties: surface tension and buoyancy. ${ }^{22,25}$ Buoyancy is related to density and surface tension is related to the viscosity of the tamponade product. The surface tension is constant around the entire interface with the retina. The buoyant force is maximal at the apex of the bubble depending on gravity and the depth of the tamponade product, which is why the postoperative position after RD is important: buoyancy can move the subretinal fluid to reattach the retina. After idiopathic $\mathrm{MH}$ surgery, buoyant force is of minor interest, since the most important feature is to obturate the hole by keeping its edges dry using the surface tension of the gas bubble, independent of buoyancy. Therefore patients are prohibited from looking up, thus allowing a permanent contact between the gas and the edges of the hole. Finally, the position of the eye after intraocular tamponade should not influence the surface tension around the $\mathrm{MH}$ if the volume of intraocular gas is sufficient.

The length of time needed to heal the $\mathrm{MH}$ remains unknown, mainly because the macula is difficult to see and an OCT cannot be performed through the gas. Using silicone oil for the intraocular tamponade provides better visualization of the fundus, and an OCT can be performed in the early postoperative period: in this condition, it was shown than a $\mathrm{MH}$ could heal as rapidly as one day after surgery. ${ }^{21,22,26}$ Closure of $\mathrm{MHs}$ with silicone oil tamponade is another 
argument for giving a secondary role to the buoyant force (buoyancy is less with silicone oil than with gas). After leakage of a vitrectomy port resulting in a $20 \%$ intraocular gas bubble at day 1, Sato observed that OCT could be performed under the bubble and assessed the closure of stage $2 \mathrm{MH}$ within the first 48 hours of the procedure. ${ }^{27}$ These findings have led some authors to propose a shorter positioning time after surgery: no difference was observed between a three-day and a seven-day positioning time (success rates: $87.5 \%$ vs $93.1 \%, P>.05),{ }^{28}$ and a success rate of $91 \%$ was obtained with a four-day positioning time and air tamponade. ${ }^{29}$ Finally, there is growing evidence that the initial size of the $\mathrm{MH}$ is correlated with the time of closure and the success rate. ${ }^{30-32}$

The anatomic results of our study are in agreement with the literature, with $92.7 \% \mathrm{MH}$ closure after a single procedure. ${ }^{11,14,29}$ The anatomic success rate of the PO group $(87.5 \%)$ is similar to other studies without the face-down position (success rates: $80 \%$ and $86 \%$ using silicone oil tamponade ${ }^{20,22}$ and $79 \%$ and $87.5 \%$ using gas ${ }^{23}$ ). However, in our study, considering all cases, the difference in anatomic results between the face-down position and seated position was significant. The visual results were good, with $61.4 \%$ of VA improvement by more than two lines. The final VA recovery seems to depend on the baseline VA, so we recommend prompt surgical treatment for idiopathic $\mathrm{MH}$ while VA remains good, as other authors have suggested. $^{23,29-31}$ Poor functional results were associated with severe $\mathrm{RDs}$ (four $\mathrm{RDs}$ required iterative surgeries for a total number of 150 eyes) or other causes of low VA (e.g., age-related macular degeneration). It is interesting to note that the rate of RDs in this study was higher than anatomic failures. This finding highlights the importance of detecting retinal breaks and RDs in order to treat them before, during, or after surgery. Indeed, the patient must be fully informed of this potential complication. ${ }^{33}$

Nevertheless, if we consider only small idiopathic MHs $(<400 \mu \mathrm{m})$, our study found no significant difference between the two postoperative positions. There was only one anatomic failure among 70 idiopathic $\mathrm{MHs}$ smaller than $400 \mu \mathrm{m}$, and this very good prognosis should lead to a less strict recommendation in terms of postoperative positioning. Older patients, for example, could adopt a more comfortable postoperative position if their idiopathic $\mathrm{MH}$ is small.

In our series, the ILM was systematically peeled without dye, a technique that is still under debate. ${ }^{5}$ We believe that it could lead to better healing of the $\mathrm{MH}$ and prevent late reopening. ${ }^{32}$ It is interesting to compare the results of our study with a recent retrospective series investigating the relationship between the size of the idiopathic $\mathrm{MH}$ and a potential benefit of ILM peeling. ${ }^{34}$ The authors con- cluded that ILM peeling could be advantageous for MHs larger than $400 \mu \mathrm{m}$ and may be unnecessary for smaller idiopathic MHs. These results suggest two different types of idiopathic $\mathrm{MH}$ management: minimal treatment for small idiopathic MHs without ILM peeling and without the face-down position and more consequential treatment for large MHs $(>400 \mu \mathrm{m})$.

The use of different gases depending on the size of the hole can be discussed. We arbitrarily chose different gases according to the size of the idiopathic $\mathrm{MH}$, using longer-acting gas for larger MHs. It is probable that the important factor is the initial contact with the edges of the hole rather than the duration of the internal tamponade. As the bubbles in the present study were always nearly complete, the influence of the type of gas was probably negligible. However, the use of different gases in our procedure remains a possible bias.

We acknowledge several other limitations to our study: nearly half of the surgeries were combined with a cataract extraction in this study, a potential bias. Some authors showed that during the combined procedure, vitrectomy can be enlarged, allowing a larger gas tamponade. ${ }^{35}$ Therefore, we could expect a higher rate of idiopathic $\mathrm{MH}$ closure in combined surgery than in a single procedure $(96.8 \%$ vs $89.8 \%)$ in our study $(P=.12)$. However, since the distribution of combined surgery was similar in both groups this bias seems acceptable. The criterion analyzed in our study was the postoperative patient position. It was difficult to closely monitor that proper positioning was respected for the length of time recommended. Therefore, patients were provided with careful explanations after surgery. We found a significant statistical difference between the two positions with a preference for the facedown position. However, we did not find any difference when the idiopathic $\mathrm{MH}$ was smaller than $400 \mu \mathrm{m}$. This could be caused by the lack of power in the subgroup analysis. However, a noninferiority trial would require 1232 eyes, which is unfeasible. The duration of the postoperative position was arbitrarily defined as five days. The literature describes a wide range for this duration and the exact time needed is still under debate, although the accepted duration is more than seven days. ${ }^{28}$

In conclusion, postoperative positioning influences the rate of $\mathrm{MH}$ closure. However, the good prognosis and the quick closure of idiopathic MHs smaller than $400 \mu \mathrm{m}$ probably make the face-down position unnecessary in selected patients. On the contrary, patients with idiopathic $\mathrm{MHs}$ larger than $400 \mu \mathrm{m}$ should ideally retain the facedown position, which is still considered the standard of care. Further prospective studies considering not only the positioning but also the size of the $\mathrm{MH}$ are warranted to confirm these results. 
Burgundy, France. The registration number of our trial is ISRCTN21076960 and the registration information is available at http://www.controlledtrials.com/ISRCTN21076960.

We gratefully thank Professor Alain Gaudric, Lariboisière, AP-HP, Paris, France for his helpful critical review of this article.

\section{REFERENCES}

1. Gass JD. Idiopathic senile macular hole. Its early stages and pathogenesis. Arch Ophthalmol 1988;106:629-639.

2. Kelly NE, Wendel RT. Vitreous surgery for idiopathic macular holes. Results of a pilot study. Arch Ophthalmol 1991;109:654-659.

3. Benson WE, Cruickshanks KC, Fong DS, et al. Surgical management of macular holes: a report by the American Academy of Ophthalmology. Ophthalmology 2001;108:13281335.

4. Thompson JT, Smiddy WE, Glaser BM, Sjaarda RN, Flynn HW Jr. Intraocular tamponade duration and success of macular hole surgery. Retina 1996;16:373-382.

5. Brooks HL Jr. Macular hole surgery with and without internal limiting membrane peeling. Ophthalmology 2000; 107:1939-1948; discussion 1948-1949.

6. Smiddy WE, Feuer W, Cordahi G. Internal limiting membrane peeling in macular hole surgery. Ophthalmology 2001; 108:1471-1476; discussion 1477-1478.

7. Yoshida M, Kishi S. Pathogenesis of macular hole recurrence and its prevention by internal limiting membrane peeling. Retina 2007;27:169-173.

8. Glaser BM, Michels RG, Kuppermann BD, Sjaarda RN, Pena RA. Transforming growth factor-beta 2 for the treatment of full-thickness macular holes. A prospective randomized study. Ophthalmology 1992;99:1162-1172; discussion 1173.

9. Smiddy WE, Glaser BM, Thompson JT, et al. Transforming growth factor-beta 2 significantly enhances the ability to flatten the rim of subretinal fluid surrounding macular holes. Preliminary anatomic results of a multicenter prospective randomized study. Retina 1993;13:296-301.

10. Thompson JT, Smiddy WE, Williams GA, et al. Comparison of recombinant transforming growth factor-beta- 2 and placebo as an adjunctive agent for macular hole surgery. Ophthalmology 1998;105:700-706.

11. Paques M, Chastang C, Mathis A, et al. Effect of autologous platelet concentrate in surgery for idiopathic macular hole: results of a multicenter, double-masked, randomized trial. Platelets in Macular Hole Surgery Group. Ophthalmology 1999;106:932-938.

12. Gaudric A, Paques M, Massin P, Santiago PY, Dosquet C. Use of autologous platelet concentrate in macular hole surgery: report of 77 cases. Dev Ophthalmol 1997;29:30-35.

13. Korobelnik JF, Hannouche D, Belayachi N, Branger M, Guez JE, Hoang-Xuan T. Autologous platelet concentrate as an adjunct in macular hole healing: a pilot study. Ophthalmology 1996;103:590-594.

14. Ezra E, Gregor ZJ. Surgery for idiopathic full-thickness macular hole: two-year results of a randomized clinical trial comparing natural history, vitrectomy, and vitrectomy plus autologous serum: Morfields Macular Hole Study Group Report No. 1. Arch Ophthalmol 2004;122:224-236.

15. Fine HF, Iranmanesh R, Iturralde D, Spaide RF. Outcomes of 77 consecutive cases of 23-gauge transconjunctival vitrec- tomy surgery for posterior segment disease. Ophthalmology 2007;114:1197-1200.

16. Ibarra MS, Hermel M, Prenner JL, Hassan TS. Longer-term outcomes of transconjunctival sutureless 25-gauge vitrectomy. Am J Ophthalmol 2005;139:831-836.

17. Eckardt C. Transconjunctival sutureless 23-gauge vitrectomy. Retina 2005;25:208-211.

18. Vincent JM, Peyman GA, Ratnakaram R. Bilateral ulnar decubitus as a complication of macular hole surgery. Ophthalmic Surg Lasers Imaging 2003;34:485-486.

19. Holekamp NM, Meredith TA, Landers MB, et al. Ulnar neuropathy as a complication of macular hole surgery. Arch Ophthalmol 1999;117:1607-1610.

20. Goldbaum MH, McCuen BW, Hanneken AM, Burgess SK, Chen HH. Silicone oil tamponade to seal macular holes without position restrictions. Ophthalmology 1998;105:21402147; discussion 2147-2148.

21. Jumper JM, Gallemore RP, McCuen BW II, Toth CA. Features of macular hole closure in the early postoperative period using optical coherence tomography. Retina 2000;20: 232-237.

22. Karia N, Laidlaw A, West J, Ezra E, Gregor MZ. Macular hole surgery using silicone oil tamponade. Br J Ophthalmol 2001;85:1320-1323.

23. Tornambe PE, Poliner LS, Grote K. Macular hole surgery without face-down positioning. A pilot study. Retina 1997; 17:179-185.

24. Merkur AB, Tuli R. Macular hole repair with limited nonsupine positioning. Retina 2007;27:365-369.

25. Whitacre MM. Principles and applications of intraocular gas. Boston, Massachusetts: Butterworth-Heinemann, 1998:939.

26. Demols P, Schrooyen M. [Analysis of optical coherence tomography for macular hole closure after surgery]. Bull Soc Belge Ophtalmol 2003:25-29.

27. Sato H, Kawasaki R, Yamashita H. Observation of idiopathic full-thickness macular hole closure in early postoperative period as evaluated by optical coherence tomography. Am J Ophthalmol 2003;136:185-187.

28. Krohn J. Duration of face-down positioning after macular hole surgery: a comparison between 1 week and 3 days. Acta Ophthalmol Scand 2005;83:289-292.

29. Park DW, Sipperley JO, Sneed SR, Dugel PU, Jacobsen J. Macular hole surgery with internal-limiting membrane peeling and intravitreous air. Ophthalmology 1999;106:13921397; discussion 1397-1398.

30. Ullrich S, Haritoglou C, Gass C, Schaumberger M, Ulbig MW, Kampik A. Macular hole size as a prognostic factor in macular hole surgery. Br J Ophthalmol 2002;86:390-393.

31. Ip MS, Baker BJ, Duker JS, et al. Anatomical outcomes of surgery for idiopathic macular hole as determined by optical coherence tomography. Arch Ophthalmol 2002;120:29-35.

32. Kumagai K, Furukawa M, Ogino N, Uemura A, Demizu S, Larson E. Vitreous surgery with and without internal limiting membrane peeling for macular hole repair. Retina 2004;24: 721-727. 
33. Guillaubey A, Malvitte L, Lafontaine PO, et al. Incidence of retinal detachment after macular surgery: a retrospective study of 634 cases. Br J Ophthalmol 2007;91:1327-1330.

34. Tadayoni R, Gaudric A, Haouchine B, Massin P. Relationship between macular hole size and the potential benefit of internal limiting membrane peeling. $\mathrm{Br} \mathrm{J}$ Ophthalmol 2006;90:1239-1241.

35. Simcock PR, Scalia S. Phacovitrectomy without prone posture for full thickness macular holes. $\mathrm{Br} \mathrm{J}$ Ophthalmol 2001;85:1316-1319. 


\section{Face-down position:}

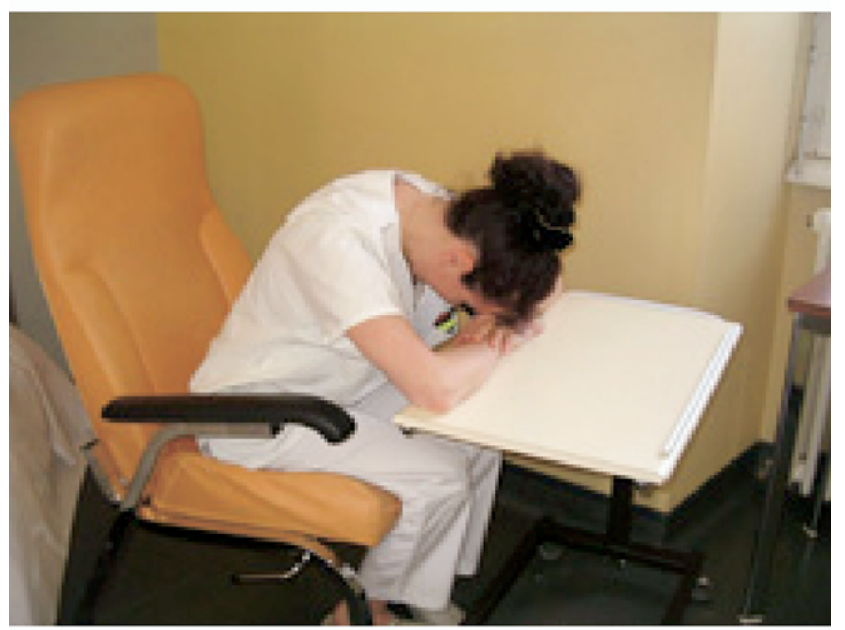

\section{Seated position:}

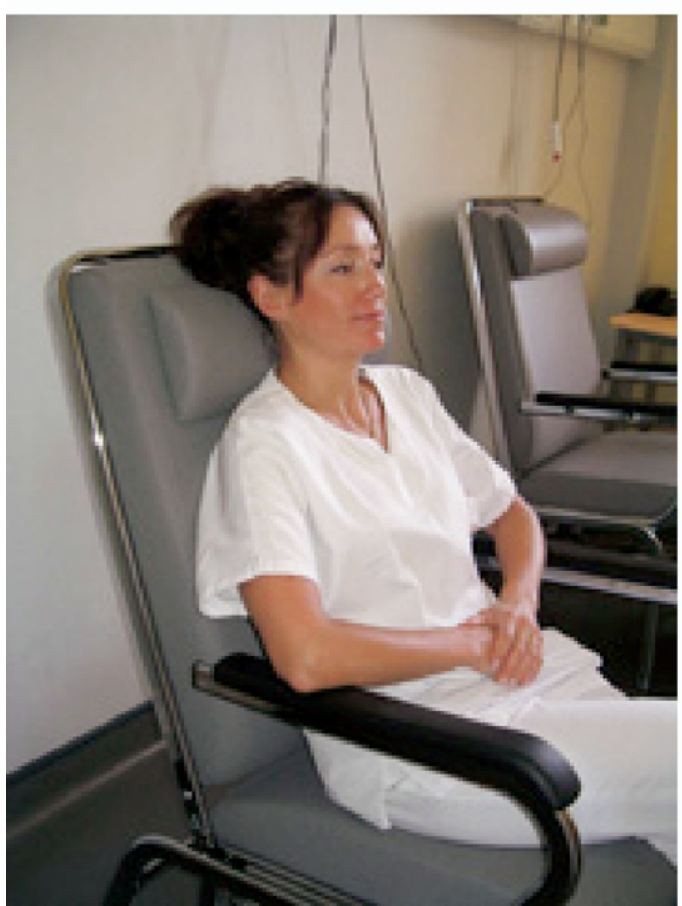

SUPPLEMENTAL FIGURE. (Top) Face-down position (Patients were asked to keep this position intermittently for at least eight hours a day). (Bottom) Seated position (Patients were only asked not to look up after the surgery). 